\title{
GERARD EN EL UMBRAL DE LOS SUEÑOS*
}

\author{
Carlos lozano QuiJada \\ Relato ganador del Certamen "Vida y Salud» de Narrativa en su IV edición \\ (modalidad estudiantes/profesionales de Enfermeria)
}

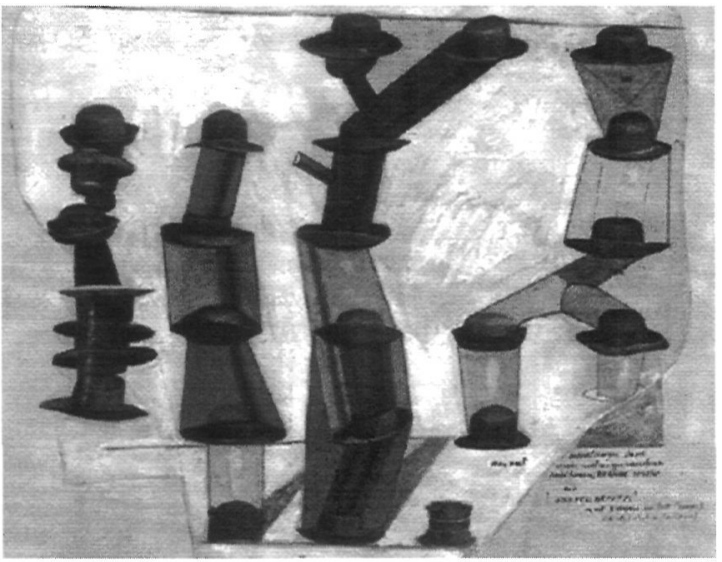

Max Ersnt «The hat makes the man»

\section{LA MAÑNA}

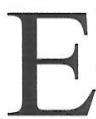
1 Sol irrumpe por la ventana de mi habitación como tantas otras mañanas y ya empieza a molestarme en la cara. Es verano y como mi madre no se levante temprano me voy a achicharrar. Ayer tuvo un día ajetreado, lo se porque estuvo toda la mañana y la tarde fuera. Cuando llegó, evitó hablar delante de mí, por lo que deduzco que fue a ver a algunos médicos. Se le olvidó cerrarme las cortinas de la ventana, y aunque yo me di cuenta, no pude decirle nada, pese a que lo intenté. A veces no me explico por que no consigo articular palabra cuando mis pensamientos funcionan a mil por hora, y lo peor es que no puedo preguntar a quienes me rodean, todo lo que desearía.

Recuerdo aquel día mejor que cualquier otro de mi vida, quizá porque creo que fue el último de una etapa. Tenía mucha ilusión en hacer ese viaje y llevaba planeándolo mucho tiempo. Trabajar en un bar no da muchos días libres, y eran mis primeras vacaciones desde hacía dos años. Carmen estaba ilusionada. Últimamente no había podido dedicarle todo el tiempo que se merecía, y era el momen- to de disfrutar el uno del otro después de tanto trabajo. Carmen es una chica muy guapa - que voy a decir yo- de veinticinco años recién cumplidos, dos menos que yo, y trabaja en un banco ya con un puesto fijo. La verdad es que no se como se pudo fijar en mi hace cinco años cuando yo trabaja en otro bar, y haber aguantado conmigo todo este tiempo. Ha tenido la oportunidad de conocer a otros chicos con más dinero y más estudios que yo, pero siempre se ha mantenido junto a mi. Me ha querido como nadie jamás lo ha hecho. Su ilusión era casarnos y tener al menos dos hijos. En este viaje los dos sabíamos que era el momento de hablar del tema, poner una fecha, y dar el gran paso. Nunca en mi vida creí que podía plantearme este momento con tanta ilusión. Siempre pensé que lo más probable es que no hiciera mas que calentarme la cabeza y llenarme de miedo. Esta vez más claro no lo podía tener, llevábamos casi cinco años juntos, y me encontraba con mas ganas que nunca. Habíamos pasado épocas difíciles por culpa del trabajo; a veces por culpa del paro, y otras por culpa de no tener tiempo para verla: horarios distintos. Esta vez, al volver de las vacaciones, me habían concedido el turno de mañanas y me hacían fijo. Por fin todo salía bien, y además, estaba con ella.

El viaje sería largo, queríamos irnos al norte de España, Asturias, Galicia..., y yo quería hacer noche en Pamplona. Salir de Alicante temprano era lo ideal: no quería andar con prisa, y así lo hicimos. Recogí a Carmen a las seis de la mañana en su casa. Lo habíamos dejado preparado todo el día antes, y el coche estaba puesto a punto. Recuerdo que cuando llegué a su portal no me dio tiempo ni a bajar del coche: ella salía en ese preciso instante. Llevaba el pelo suelto y aunque la ropa que llevaba era algo cómoda y nada del otro mundo, me quedé mirándola pensado lo bonita que era, y más aún, lo mucho que necesitaba a esa persona para 
sentirme así de feliz. Estaba preciosa y los segundos que pasaron hasta que pude tocarla y besarla me parecieron mucho más lentos de lo normal. Tuve la sensación de que todo estaba enlentecido, y por instantes me sentí ansioso, impaciente; quise que llegara antes de lo que pudo hacerlo.

Cuando al fin iniciamos el viaje ella no hacía mas que sonreír. Hablaba de las muchas ganas que tenía de pasar diez días conmigo tranquilamente, al mismo tiempo que no dejaba de pasarme la mano suavemente por el pelo. Recuerdo perfectamente aquella dulce sensación. Lo recuerdo tal como si ahora mismo me estuviera acariciando, aunque lo cierto es que sigo notando el cada vez mas molesto sol en mi mejilla.

¡Al fin oigo ruido en la casa! Parece que mi madre se ha levantado. No tardará en venir a darme el beso de buenos días, con su cara cansada y triste. No se lo reprocho, pero me encantaría verla sonreír como antes, cuando no tenía que cuidar de mí y se reía con los chistes que le contaba; jsi ahora pudiera contarle alguno! Ya está aquí, cada día parece algo mas vieja, y hoy parece que está más cansada de lo normal. Ya siento sus labios en mi mejilla acalorada, y ya se ha dado cuenta de mi molesto sol; al fin corre las cortinas lo justo para que entre luz y no me moleste. Siempre es parca en palabras justo después de levantarse, pero ahora cuando me traiga el desayuno empezará a decirme cosas bonitas. Normalmente da la sensación de que me habla como si yo tuviera cinco años, pero me encanta que me diga todas esas cosas.

Recuerdo de nuevo esa dulce sensación en mi pelo. Siempre que me siento débil pienso en esas caricias que Carmen me daba. Cuantas horas habré pasado intentando sentirlas tal como las sentí entonces, cuanta vida me dará el solo recuerdo de ella a mi lado. Antes no podía vivir sin ella y se que ahora tampoco. Como la echo de menos, como me gustaría que estuviera aquí conmigo, como me gustaría verla ahora mismo. ¿ Por que no vendrá a verme?

Aquella mañana de primavera, cuando comenzábamos nuestro viaje, llegó un momento en el que ella se durmió mientras yo conducía. Me encantaba verla dormir. Estuvo durmiendo media hora y luego abrió sus castaños ojos, me cogió la mano, y me dijo que había soñado con nosotros.
Dijo que después se lo recordara para contarmelo, y que me quería. Por última vez vi como se cerraban sus bellos ojos, y continué conduciendo tan feliz como un niño con zapatos nuevos. Me pregunté que fue lo que habría soñado, me hubiera encantado saberlo entonces. Continué conduciendo, mientras con una mano acariciaba la suya. Era un placer recorrer sus dedos, buscar recovecos, notar cada pliegue, cada línea de su palma, su personal suavidad... veía tanto por descubrir en una simple mano.

Era una carretera nacional, el Sol comenzaba a salir, y me deleitó tiñendo el cielo de unos colores anaranjados y violetas, que merecían la más pura admiración. No circulaba nadie delante de mí, solamente se acercaba un camión en dirección contraria. El amanecer adornaba con el colorido tapiz de luminosidad a sus espaldas, y aunque parecía no llevar nadie detrás, surgió un coche iniciando el adelantamiento. - No se atreverápensé, pero me equivoqué. Veía como estaba en pleno adelantamiento, y me di cuenta que era imposible que le diera tiempo. No puede ser, no nos puede pasar esto. Miré a mi derecha y la vi durmiendo. Me dio tiempo a pensar incluso en lo bonita que era, y mi pensamiento fue "Carmen no te despiertes". Lo siguiente que recuerdo es una luz intensa y un fuerte olor a medicamentos: los odio.

Estuve un rato intentando averiguar dónde estaba. Quise mirar a mi alrededor, pero mi cuello no me permitió mucho. ¿Qué me ocurre? pensé. Me propuse levantar la mano, pero por una parte no sabía donde la tenía, y menos aún, conseguí levantarla.

Empecé a darme cuenta de lo que me ocurría, y sentí como unas lágrimas recorrían los surcos de mis mejillas; una enfermera se acercó, y al verme los ojos abiertos llamó a otra. Parece ser que se alegraron, pero luego, con una gasa quisieron secarme las lágrimas. Intenté decirles que no lo hicieran, que quería notarlas caer por mi cara. Era lo único que sentía. No pude decirles nada: las secaron. Pocos días después, recuerdo que me trajeron a casa en una ambulancia, a mi hogar de siempre. A mí eso no era lo que me preocupaba; yo quería saber dónde estaba Carmen, cómo estaría, y por qué no había venido a verme. 
Creo que llevo mas de tres meses en casa, mas uno que debí pasar en la UCI, y todavía no he conseguido saber nada de Carmen, ni tan siquiera oír su nombre. Paso las veinticuatro horas del día entre esta jodida cama y el aún más odioso sillón. No puedo mover apenas ningún músculo del cuerpo e incluso tengo en el cuello un agujero con un tubo a lo que llaman traqueo y cánula. De lo más engorroso. Me cambian la cánula tres días por semana, y viene un enfermero de pelo cano a hacerlo; a mis padres les da miedo. Hoy, si no me equivoco le toca, y no creo que tarde, pues suele venir temprano. Es agradable, intenta hablar conmigo, y casi siempre me coge de la mano, aunque sólo creo sentir algo si me coge fuerte.

Mi madre me está dando el desayuno; una papilla que me gusta dentro de lo que cabe, y que a pesar de ello, me cuesta tragar. Ella, como siempre, diciéndome lo guapo que soy. Ahora se acerca mi hermana para darme su beso de buenos días; me gusta. Oigo la puerta de casa abrirse y por los pasos creo que es mi padre. Trabaja en el turno de noche de la fábrica porque gana más, y por lo que oigo, parece que estamos necesitados. Se acerca a mí, y me da, como no, otro beso, al tiempo que me coge la mano, y me pregunta "¿Cómo estás, Gerard?". Me gustaría contestarle, pero no puedo mas que emitir un ligero sonido; de todas formas, no le iba a contestar que bien.

Tengo a los tres frente a mí, mirando cómo desayuno, y tengo la sensación de que sienten pena. Todos los días están ahí, cuidándome, y a pesar de que hay días que se les ve desanimados, al día siguiente siempre vuelven a estar aquí. Lo pienso a veces, y soy yo quien tiene pena por ellos, todo el día pendientes de mí, limitando sus vidas por culpa de un inútil como yo. Miro por la ventana, ahora ya solo en mi habitación, y veo un gorrión danzarín en la cornisa. El cielo azul de hoy parece muy intenso, y deduzco que la playa debe estar hoy hasta los topes.

$\mathrm{Me}$ he quedado tan embobado que no he oído ni el timbre, ni a Pedro, el enfermero, entrar en mi cuarto. Que me cambien la cánula es algo que me resulta muy desagradable, pero parece ser necesario para que respire bien. Normalmente de forma instintiva ofrezco resistencia a que me la cambien, pero si esperan un poco y consiguen tranquilizarme, suele ser algo muy rápido, aunque no deja de disgustarme.

Hoy ha sido de las veces que menos me ha molestado, y Pedro ya se despide de mí. Como siempre me dice " Hasta luego, Gerard". Coge mi mano y se va. Esta vez se gira antes de salir por la puerta y me mira entristecido un segundo antes de cruzar el umbral. Me pregunto: ¿es un adiós lo que he visto en él? Últimamente parece más serio de lo normal, y yo creo que hay algo que no le va bien; me gustaría preguntarle " ¿qué te ocurre, Pedro?", pero me quedo con las ganas. Me gusta imaginarme como será su vida: si tendrá mujer e hijos, si le gusta el deporte, la música, etc., digamos que es una forma de entretenerme cuando no quiero pensar en Carmen, en mi familia, y en mí. Pedro es la única persona ajena a mi familia que me visita frecuentemente, aunque sea por obligación. Ahora se quedará unos minutos como siempre hablando con mis padres, y luego se marchará hasta el próximo día; espero.

Ya no está el gorrión en la ventana, es una pena porque me distrae bastante el mirar a los pajarillos. Por simple rutina se lo que me toca después de que Pedro se vaya: el baño. Entre mi padre y mi madre me cogen, moviéndome para un lado y otro, y con una esponja enjabonada y agua caliente, me hacen una higiene completa. Antes me daba vergüenza, pero ahora ya me he acostumbrado: que remedio me queda.

Terminan de asearme, y me llevan a mi sillón del comedor, al lado de la ventana, en la cual mi madre siempre coloca un trozo de pan para atraer a los pájaros. Debe haberse dado cuenta de lo mucho que me entretienen. Suelo recordar al mirarlos, que de pequeño siempre deseaba ser como uno de ellos para poder volar. Que sensación mas impresionante debe tenerse al observar todo desde arriba, dejándote llevar por el viento, y saber que no hay nada que te sujete, nada que te ate. Ser parte de ese aire que respiramos y sentir la fuerza del viento en tus propias alas. Ahora me conformaría con encontrarme de pie en lo alto de una colina, sintiendo un fresco viento sobre mi rostro, de tal forma que no se me pudiera escapar ninguna de las sensaciones producidas por el choque de mi piel contra ese ser invisible e intangible. Veo tanta grandeza en un momento así, que creo que, a pesar de todo, nunca 
se valora con su verdadera importancia, almenos hasta que, como yo, uno no puede tenerlo.

Mi madre ha puesto la radio con el volumen bastante bajo, lo que significa que mi padre ya está durmiendo. Clara, mi hermana, creo que se ha ido a hacer la compra y mi madre está limpiando la casa. La oigo tararear y es algo que me gusta, da la sensación de olvidarse un poco de mí y disfrutar. A mí me gusta que estén todo el día pendiente de mí, pero sé que ellos no deben cargar sólo con mi peso, han de tener su propia vida; hay ratos en los que sería mucho más feliz si supiera que se han ido los dos a pasear tranquilamente, que quedándose aquí haciéndome compañía. Como no, intento decírselo, pero los esfuerzos son en vano.

Se oye la puerta: es Clara. Ha vuelto de comprar y viene cargada de bolsas. Clara es casi siete años más joven que yo y aunque ya se le está pasando "la edad de pavo", vive una época en la que todo son follones con chicos. A menudo se sienta a mi lado y comienza a contarme cosas que le ocurren, incluso me pide consejo, y aunque no puedo contestarle, ella siempre parece saber lo que yo le diría; a mí me encanta que me cuente sus cosas, incluso yo diría que ahora me cuenta más que antes. Suele pasar mucho tiempo conmigo y es una de las cosas que más apoyo me da. Quisiera que disfrutara de la vida todo lo que yo no puedo.

Suena el teléfono y Clara lo coge rápidamente. Parece ponerse nerviosa y lo único que dice es "sí" y "vale", para terminar diciendo "hasta luego". Por lo visto era el chico que le gusta y han quedado esta tarde; está radiante de felicidad. Me encanta verla así, solo me faltaría darle un abrazo, aunque ya viene ella, como si me hubiera oído, y como buenamente puede, me lo da. Ahora me dará de comer, y después me leerá durante una hora un libro para entretenerme en la hora de la siesta. Ayer acabamos un libro y hoy toca empezar otro: ya veremos que tal.

\section{LA TARDE}

La tarde va a ser larga; Clara ya se ha marchado y no creo que vuelva hasta la noche. Me ha comenzado a leer una novela policiaca, que parecía bastante interesante, pero hoy sólo me ha leído media hora; tenía que arreglarse para irse con el chico de la llamada. Se ha puesto una falda que me encanta, con una blusa roja, y además apenas se ha maquillado, lo cual prefiero. Cuando ha salido del cuarto y me ha preguntado que tal, he asentido lo suficiente para que supiera que le daba sobradamente mi visto bueno. Por ahora no ha tenido mucha suerte con sus relaciones, y espero que esta vez le vaya mejor.

¡Vaya!, se ha colado una puñetera mosca en casa, y está rondando por aquí. Ya se ha posado sobre mi mano, y la condenada se está entreteniendo con mi vello. No es que la sienta lo más mínimo, pero mi vista si que alcanza a verla y me pongo muy nervioso. He de mover la mano lo suficiente como para espantarla, pero lo único que consigo es que de un pequeño vuelo y que se vuelva a posar. No se dará cuenta de lo mucho que me molesta. ¿Podría este bicho mirarme y tener algo de compasión por mí?; ipues no!, todo lo contrario, ahora la graciosa se ha posado en mi mejilla derecha, y esto es algo que sí siento. Consigo dar una pequeña sacudida, con la cabeza esta vez, y parece que se va, aunque cómo no, vuelve. ¿No hay nadie en casa que se de cuenta?, ¡mamá, ven rápido!, pienso ya impacientándome; no me apetece pasar la tarde pendiente de la pequeña voladora. $\mathrm{Mi}$ madre está en la cocina, la oigo, pero me parece que no voy a tener suerte y por ahora no va a venir. Qué rabia me da no poder quitármela de encima; ahora está paseándose por mi frente, y cada vez hace menos caso a mis sacudidas, está acabando con mi paciencia. Se dirige a mis párpados y esto creo que ya es pasarse de la raya, pero... ipor fin!, vuela, ¿vuelve?... ¡no!... espero.

El timbre incompasible del teléfono vuelve a irrumpir en el ligero silencio de la casa. Suena tres veces y esta vez es mi padre quien lo coge; si está levantado es que deben ser pasadas ya las siete de la tarde. Él como siempre, es escaso en palabras cuando habla por teléfono, y no consigo enterarme con quién habla, aunque durante un momento de la conversación me mira como si pudiera tener algo que ver conmigo. Cuando cuelga, le oigo decir a mi madre que Isabel y Juan, los padres de Carmen, van a venir dentro de un rato a casa. ¿Y Carmen, por qué no viene?, ¿qué ocurre?, tal vez simplemente no ha dicho su nombre, pero también viene; 
quiero creer eso. ¿Cuánto tardarán? media hora, una hora, ¿más?. Y si Carmen no viene, ¿me dirán por qué?; no puede ser, tiene que venir.

El tiempo pasa muy lento. Una hora puede resultar eterna, quizá por que en ello se me vaya la vida, o quizá por que no pueda controlar el miedo a que ella no aparezca por la puerta. Quiero verla, quiero sentirla, quiero que me mire con sus castaños ojos y que me diga "tranquilo, esto no es más que un mal sueño". ¿Qué ocurre?, ¡ah! con que me llevan de nuevo a mi cuarto; ipues no quiero! Sé que es la hora, pero deseo quedarme en el comedor. Deben preferir no dejarme allí, para después hablar con tranquilidad, ¿con tranquilidad de qué?... no lo entiendo.

Por fin suena el timbre de la puerta, ¿serán ellos? quién si no. Mi puerta está abierta, en un momento saldré de dudas. Siento mi mejilla moverse con un imparable tic, serán los nervios, ¡tengo miedo!. Ya están aquí, Juan... Isabel... mis padres... y detrás... nadie; ¿No viene Carmen? ¿por qué?, ¿no quiere verme?... ique alguien me conteste! Lo siento, me alegro de verles pero díganme donde está su hija, por favor... por favor. Isabel 'me coge de la mano y me pregunta que tal estoy. Como voy a estar: jodido. Isabel, míreme a los ojos y conteste a mis preguntas. Durante dos segundos se queda totalmente fija en mis ojos, adivinando las preguntas que le formulo, y yo incluso, puedo intuir mi degradada imagen sobre su dolida pupila. Se gira un momento y pregunta a mi madre si me lo han dicho, ¿ si me han dicho qué?, ¿qué?... Dios mío, esto parece una película, ¿alguien quiere contestarme? Mi madre niega con la cabeza, al tiempo que la agacha, y de repente Isabel arranca a hablar al tiempo que los ojos se le humedecen. "Gerard, Carmen no pudo..." la lágrima ya recorre su arrugada mejilla, —icontinua! pienso-_... no pudo sobrevivir". ¡No puede ser, ella no!, a ella no le puede haber pasado nada. No me lo creo, quiero despertar, que alguien me diga que no es cierto. ¡Papa! mírame, mírame a los ojos y dime que ella va a venir a verme, que va a acercarse a mí y me va a dar un beso, que está bien, y que lo único que ocurre es que no quiere verme en esta situación. Por favor, ¡Carmen no!, ella es la única que puede ayudarme; con su ayuda seguro que mi estado incluso mejoraba. Dejad de decir tonterías, dejad de decir que ella ya no está aquí, yo sólo quiero oír, que ella está bien y que va a venir, ¡decidlo de una vez ! No quiero vuestros besos de despedida, sólo la quiero a ella; no quiero vuestra compasión, sólo la quiero a ella; no me importa estar así, si ella está bien; no quiero vivir, ...si no está ella.

Parece que se van; la visita ha sido más corta de lo que me imaginaba, se ve que está conversación, por llamarlo de alguna manera, no ha sentado bien a nadie. ¿Ahora qué? como voy a despertarme cada mañana sabiendo que ella nunca va a aparecer por esa puerta, como van a pasar los días ante mí, sin la más mínima ilusión de volver a oler su perfume, de volver a ver sus labios sonreír, y volver a sentir su suave tacto.

Mi madre entra por la puerta con la papilla de la cena; no quiero, no tengo hambre, no sería capaz de tragar ni la más mínima cantidad. Lo siento, mamá, no me pidas que coma que no lo voy a hacer, lo escupiré como pueda. Mamá, ¿por qué me ocurre todo esto a mí? ¿Por qué el golpe que me di en la cabeza no fue mayor y así haber acabado con esto?, al menos de esta forma, me hubiera marchado con Carmen. Mamá, tú que siempre has cuidado de mí, y siempre has tenido una respuesta para todo, contesta ahora a mis preguntas. No las ignores, aunque no me oigas, seguro que conoces en qué sentido van mis pensamientos. Mamá, papá, ¡ayudadme! Tengo ante mí a mis padres, y en este momento casi no son capaces de mirarme a los ojos. Siento su miedo, el temor de la verdad, y siento el sufrimiento de aquellos que me dieron la vida, para que la viviera de cualquier manera menos de esta. Y yo me pregunto: ¿es vida lo que tengo?

\section{LA NOCHE}

La luz se apaga, mientras veo en la puerta, el contraste de la luz del comedor en mis padres. Oigo un temeroso, y al mismo tiempo dulce, "hasta mañana", al que curiosamente mi pensamiento contesta con "yo también os quiero". Veo a través del cristal de la ventana cómo la oscura noche se impregna de una cantidad de estrellas infinita, y un cielo en el que se distinguen con una claridad mayor de lo usual. Si yo pudiera alcanzar alguna de ellas, quizá sería incluso capaz de llegar 
hasta Carmen. Mi corazón que hasta hoy a latido con el único fin de ser acompañado por el de otra persona, es el único que me mantiene con vida. Noto el dolor de cada uno de los latidos, ahora obligados por una parte de mi cerebro a la que no puedo dominar. Siento la soledad de un músculo que parece ser capaz de sentir el dolor, y trasmitirlo de forma inevitable al resto de mi insensible cuerpo.

Oigo la puerta de casa abrirse, lo cual me saca de mis elucubraciones. Debe ser Clara, pienso, y no me equivoco al sentir su presencia en mi cuarto. Noto un intenso beso en la mejilla, quizá más sentido de lo normal, que posterga el relato de su noche, hasta mañana. Se despide con una ligera caricia, y me desea "felices sueños" al alejarse de mí. - Adiós - contesto en silencio.

Vuelvo a sentir la soledad de mi cuarto, que en este momento es más bien una fiel compañera. Recupero la sensación de los que cada vez me parecen mas espaciados latidos. ¡Dios, cómo la necesito! quiero gritar su nombre, Carmen. Quiero invocar al cielo para que la traiga conmigo, y no consigo ni emitir el más mínimo sonido. Siento mis húmedos ojos deseosos de deleitarse con su imagen, y lo único que consigo es la imparable lágrima que me recuerda quien soy. Mi cuerpo se estremece por un llanto limitado en su apariencia, y mucho más intenso en mi interior, al tiempo que grito a mi mismo " $i$ Carmeeeeen!".

Siento la pesadez de los ojos que inexplicablemente no soy capaz de mantener abiertos. Parece haber transcurrido mucho tiempo desde el último latido. Veo un color claro, luminoso, que parece darme vida. Reconozco el color del rostro de Carmen, y me acompaña el inequívoco y dulce olor de su piel. Sólo con su olor sería capaz de reconocerla. — ¿Estás aquí!, jeres tú!, estás preciosa, te veo con mis ojos, siento como la dulce sensación de tu aroma recorre mi cuerpo como si mi propia sangre fuera y... Señor mío... puedo cogerte de la mano; está caliente, y sigue igual de suave, igual de perfecta. Sabía que no me dejarías solo-. Noto la intensa caricia que reparte por mi cabello, y oigo sus palabras que dulcemente me dicen "cruza conmigo... a esta parte de los sueños".

Mientras camino con ella de su mano, me recreo en el placer del fresco viento en mi rostro, y en la anhelada sensación de mi cuerpo, que ahora creo percibir más que nunca. Me pregunto si estoy en un sueño y no busco la contestación. Ahora me siento feliz, y siento un corazón pleno de fuerza y vida, pese a saber... que ya ha dejado de latir.

- En la vida hay cosas que son reales.

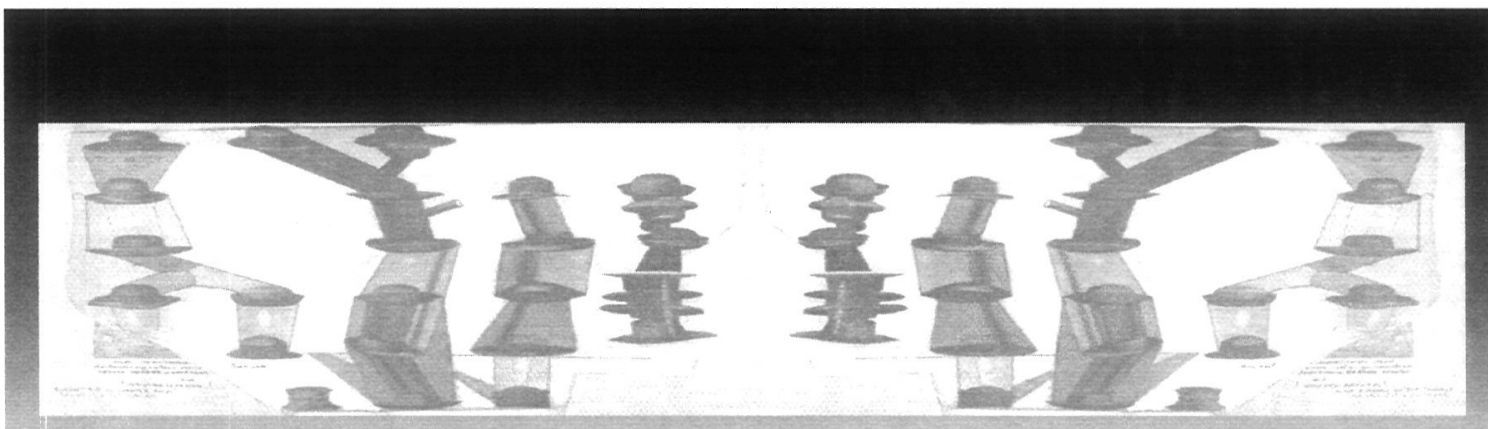

